cd revised 11/19/90--Yoo MRS Symp. Proc. Paper Version 4 (DISK 9)

\title{
THE ROLE OF TWINNING IN BRITTLE FRACTURE OF Ti-ALUMINIDES*
}

M. H. YOO, C. L. FU, AND J. K. LEE ${ }^{\dagger}$

Metals and Ceramics Division, Oak Ridge National Laboratory, Oak Ridge, TN 37831

\section{ABSTRACT}

\section{DE91 005506}

The important roles of (111)[112] twinning in cleavage fracture of single phase $\gamma$-TiAl and $\mathrm{TiAl}_{3}$ are assessed on the basis of theoretically calculated elastic constants, shear fault energies, and cleavage energies. The importance of elastic anisotropy in both homogeneous twin nucleation theory and dislocation models for twin nucleation is emphasized. The twin-slip conjugate relationship makes an important contribution to the strain compatibility for localized plasticity at a crack-tin of Mode-I type. The intrinsic brittleness of these aluminides is attributed to a combined eifect of the low mobility of slip and twin dislocations and the relatively low cleavage strength. Effect of the resolved normal stress on the twin plane is to enhance twinning activity at a (110) crack-tip, leading to transformation toughening of shear type.

\section{INTRODUCTION}

The importance of deformation twinning in mechanical behavior of intermetallic compounds has been emphasized recently in a number of overview papers [1-4]. In the $\mathrm{L} \mathrm{l}_{0}$ type and the $\mathrm{DO}_{22}$ type tetragonal crystal siructures, the role of deformation twinning in generalized plastic deformation and fracture toughness is of special importance because the so-called 'ordered twinning' (or true twinning) is possible in these structures. A sharp brittle-to-ductile (BDT) transition has been reported in TiAl [5] and $\mathrm{TiAl}_{3}$ [6] of the $\mathrm{Ll}_{0}$ and $\mathrm{DO}_{22}$ structures, respectively. This BDT phenomenon has been attributed to the increasing activity of 1/2[110] dislocations [7-10] and/or (111)[112] micro-twinning [10-13] with increasing temperature. Since $[110](001)$ is the conjugate slip system to the anti-twinning system [11], i.e. (111)[112], this twin-slip conjugate relationship is expected to contribute significantly to the strain compatibility for high temp ature plasticity.

The purpose of this paper is to report the results of anisotropic shear strain at a Mode-I type crack-tip in TiAl and $\mathrm{TiAl}_{3}$. The recent results of first-principles calculations of elastic constants, twin boundary energies, and cleavage energies are reviewed first. The current understanding of twin nucleation and growth in Ti-aluminides is briefly summarized. Finally, a transformation (shear) toughening mechanisrn is proposed for both cubic and non-cubic ordered intermetallic alloys.

\section{BULK AND DEFECT PROPERTIES}

\section{Crystallosraphy of Twinning}

The crystal structures of $\mathrm{TiAl}$ and $\mathrm{TiAl}_{3}$ are shown in Fig. 1. The two crystal structure types $\left(\mathrm{Ll}_{0}\right.$ and $\left.\mathrm{DO}_{22}\right)$ are both ordered superlattice structures based on the fcc structure. The $\mathrm{Ll}_{0}$ type is the face-centered tetragonal $(\mathrm{fct})$ structure consisting of atomic layers perpendicular to the $\mathrm{c}$ axis. The $\mathrm{DO}_{22}$ type is related to two $\mathrm{Ll}_{2}$ type unit cells stacked along the $\mathrm{c}$ axis with an

\footnotetext{
* Research sponsored by the Division of Materials Sciences, U.S. Department of Energy, under

contract DE-AC05-84OR21400 with Martin Marietta Energy S 'icms. Inc.
Permanent address: Deparment of Metallurgical and Materials En_ineering. Michigan
Technological Universitv. Houghton. MI 49931

Technological Universitv. Houghton. MI 49931 

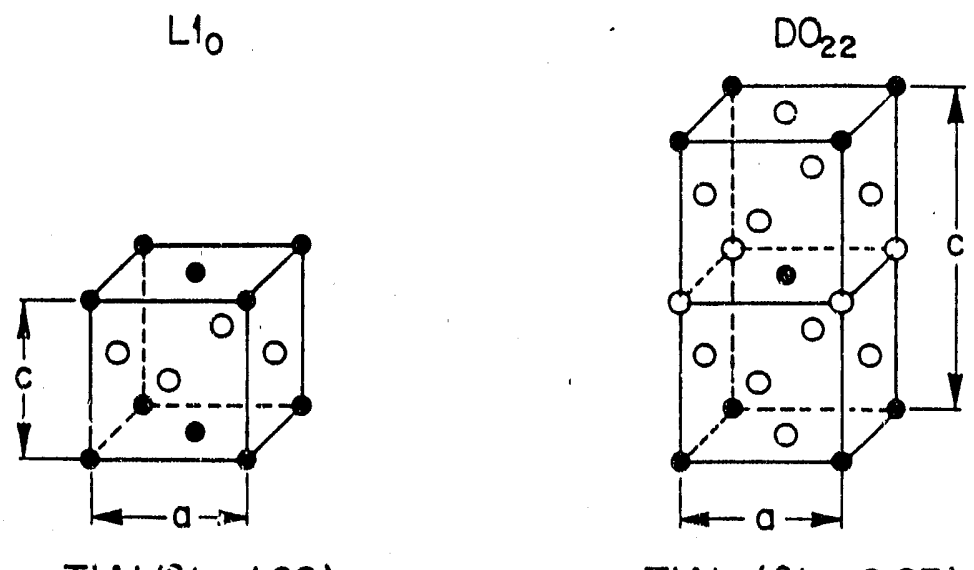

$\operatorname{TiAl}(\% / \%=1.02)$

$\mathrm{TiAl}_{3}(\mathrm{C} / \mathrm{q}=2.23)$

Fig. 1. $\mathrm{L}_{0}$ type and $\mathrm{DO}_{22}$ type crystal structures.

antiphase boundary (APB) of $1 / 2[110](001)$ type at every other (001) plane. The Miller indices for the $\mathrm{DO}_{22}$ structure are referred to the fct lattice, i.e., $\mathrm{c}^{\prime} / \mathrm{a}=1.115$ for $\mathrm{TiAl}_{3}$.

Possible slip and twin modes of plastic deformation are shown with the $\mathrm{L} 1_{0}$ structure (Fig. 2). In the $\mathrm{DO}_{22}$ structure, the magnitudes of Burgers vectors for both superdislocation and 'ordinary' dislocation, [101] and $1 / 2[110]$, shown in Fig. 3(a) must be doubled to 2[101] and [110], respectively, hence both becoming superdislocations. With respect to the (111) $1 / 2[11 \overline{2}]$ primary twin system the complementary twin (anti-twinning) direction, [112], is shown in Fig. 3(b) together with its conjugate (001)[110] slip system. It is this slip-twin conjugate relationship [11], as will be discussed later, which offers a particularly attractive geometrical condition for enhancement of localized slip and twinning at a crack-tip.

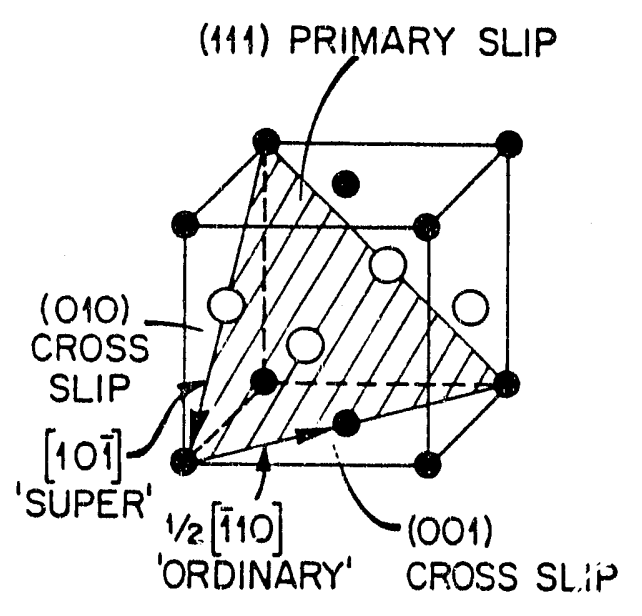

(a) SLIP MODES

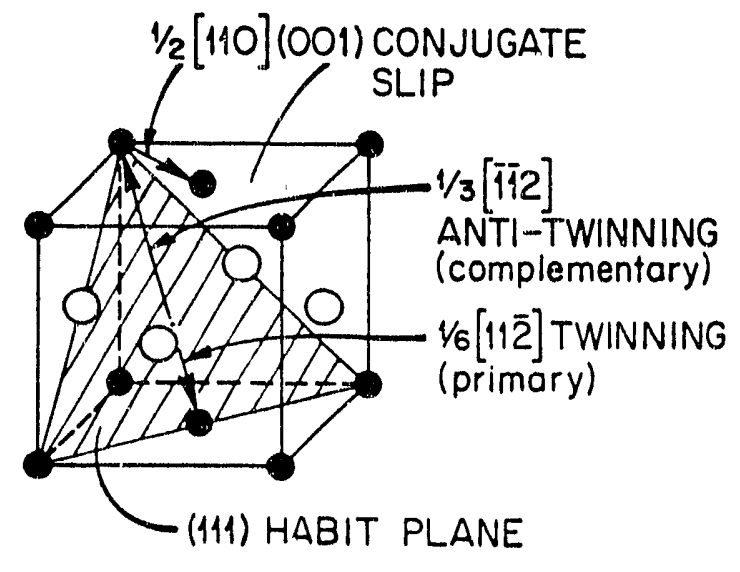

(b) TWIN MODES

Fig. 2. Possible deformation modes in the $\mathrm{L} 1_{0}$ structure. 


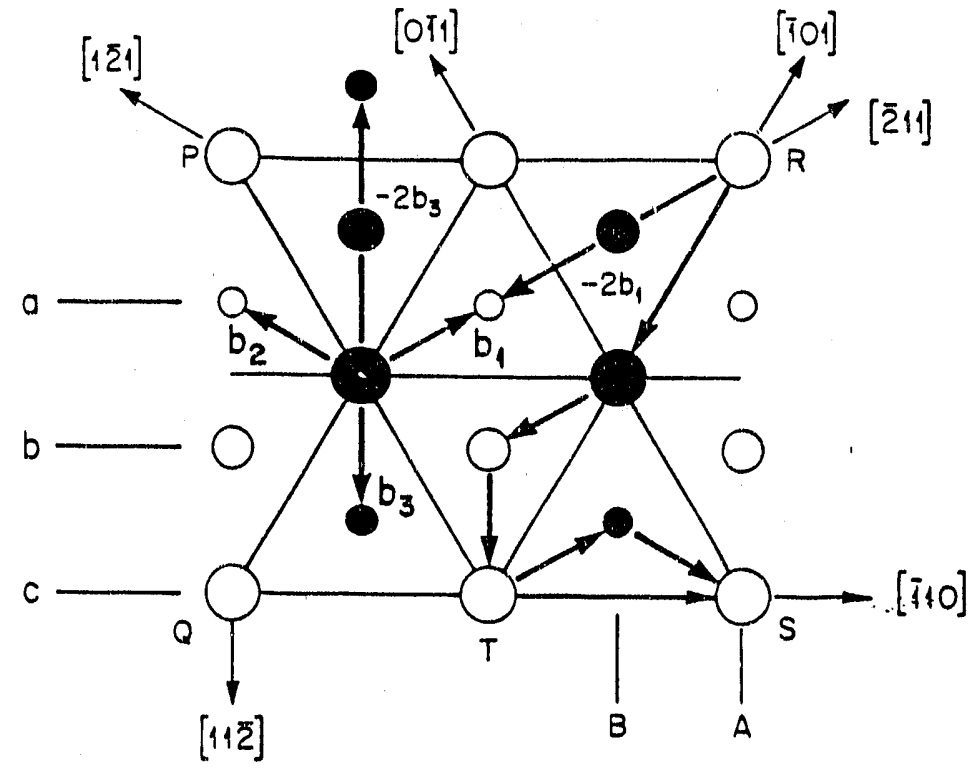

Fig. 3. Atomic stacking sequence of three (111) layers in the $\mathrm{Ll}_{0}$ structure.

Figure 3 shows the atomic stacking sequence (abc) on the (111) plane of the L $1_{0}$ structure. All the vectors shown in Fig. 3 lie in the (111) plane - the c layer. There is only one distinct "true twinning" with $b_{3}=1 / 6[11 \overline{2}]$ that does not alter the $\mathrm{L} 1_{0}$ structure upon twinning, hence also called "ordered twinning." The other partial dislocations with $b_{1}=1 / 6[211]$ and $\bar{b}_{2}=1 / 6[121]$ lead to "pseudo-twinning."

\section{Elastic Anisotropy}

First-principles total-energy calculations of the elastic constants of $\mathrm{TiAl}$ and $\mathrm{TiAl}_{3}$ were made using the full-potential linearized augmented plane-wave (FLAPW) method [14,15]. The calculated elastic constants are listed in Table I. It is interesting to note that there is a substantial difference between $\mathrm{C}_{44}$ and $\mathrm{C}_{66}$ values, indicating the anisotropic character of atomic bonding between adjacent planes in different directions. In TiAl, the shear anisotropy factor for the [101] shear direction, $A_{2}=4 C_{44} /\left(C_{11}+C_{33}-2 C_{13}\right)=2.46$, is larger than that for the the [110] direction, $A_{1}=2 C_{66} /\left(C_{11}-C_{12}\right)=1.18$. A large $A_{2}$ value is indicative of the fact that strong cohesion between pure titanium and pure aluminum layers. It is this directional Ti-Al bonding which hinders the mobility of [101] superdislocations [9]. In TiA. $]_{3}$, on the other hand, the opposite holds true, i.e. $A_{2}=0.25$ and $A_{1}=2.54$. The relatively small value of $A_{2}$ is indicative of the fact that $\mathrm{TiAl}_{3}$ is marginally stable with respect to the [110] shear on the (001) plane.

Table I. Calculated elastic constants in units of $10^{5} \mathrm{MPa}$

\begin{tabular}{ccccccc}
\hline & $\mathrm{C}_{11}$ & $\mathrm{C}_{12}$ & $\mathrm{C}_{13}$ & $\mathrm{C}_{33}$ & $\mathrm{C}_{44}$ & $\mathrm{C}_{66}$ \\
\hline $\mathrm{TiAl}$ & 1.90 & 1.05 & 0.90 & 1.85 & 1.20 & 0.50 \\
& & & & & & \\
$\mathrm{TiAl}_{3}$ & 2.02 & 0.88 & 0.60 & 2.43 & 0.20 & 1.45 \\
\hline
\end{tabular}




\section{Twin Boundary and Cleavage Energies}

Using a supercell approach by introducing periodic planar stacking faults [16], we estimated earlier the (111)[112] twin boundary energy of TiAl to be $60 \mathrm{~mJ} / \mathrm{m}^{2}$ [2]. The twin boundary energy of $\mathrm{TiAl}_{3}$ is obtained by comparing the total-energy difference between the matrix lattice abcdef layer stacking sequence on the (111) plane and the twinned superlattice with an abcbaf layer sequence. We obtained the twin boundary energy of $140 \mathrm{~mJ} / \mathrm{m}^{2}$ for TiAl 3 . Twinning should be the dominant deformation mode for $\mathrm{TiAl}_{\text {and }} \mathrm{TiAl}_{3}$ due to their boundary energies.

Ideal cleavage energy, defined as the energy required to separate the solid into two semiinfinite crystals, of TiAl was determined earlier for (110), (001), and (100) planes to be 5.3, 5.6, and $4.6 \mathrm{~J} / \mathrm{m}^{2}$, respectively [9]. No surface relaxation or surface reconstructions are included in the estimate of cleavage energy. Since the cleavage energies are not particularly low, it appears that the brittle fracture of TiAl at low temperatures is not caused by the intrinsic cleavage energy effect alone.

\section{TWIN NUCLEATION AND GROWTH}

\section{Classical Homogeneous Nucleation Model}

By applying the elastic inclusion theory [17] and the shape bifurcation theory [18], we have recently analyzed the effects of applied stress on the elastic strain energy of an ellipsoidal twin in tetragonal crystals [19]. The orientation dependence of the free energy change of twinning with respect to the direction of uniaxial compression in $\mathrm{TiAl}_{3}$ is shown in Fig. 4, where the axis

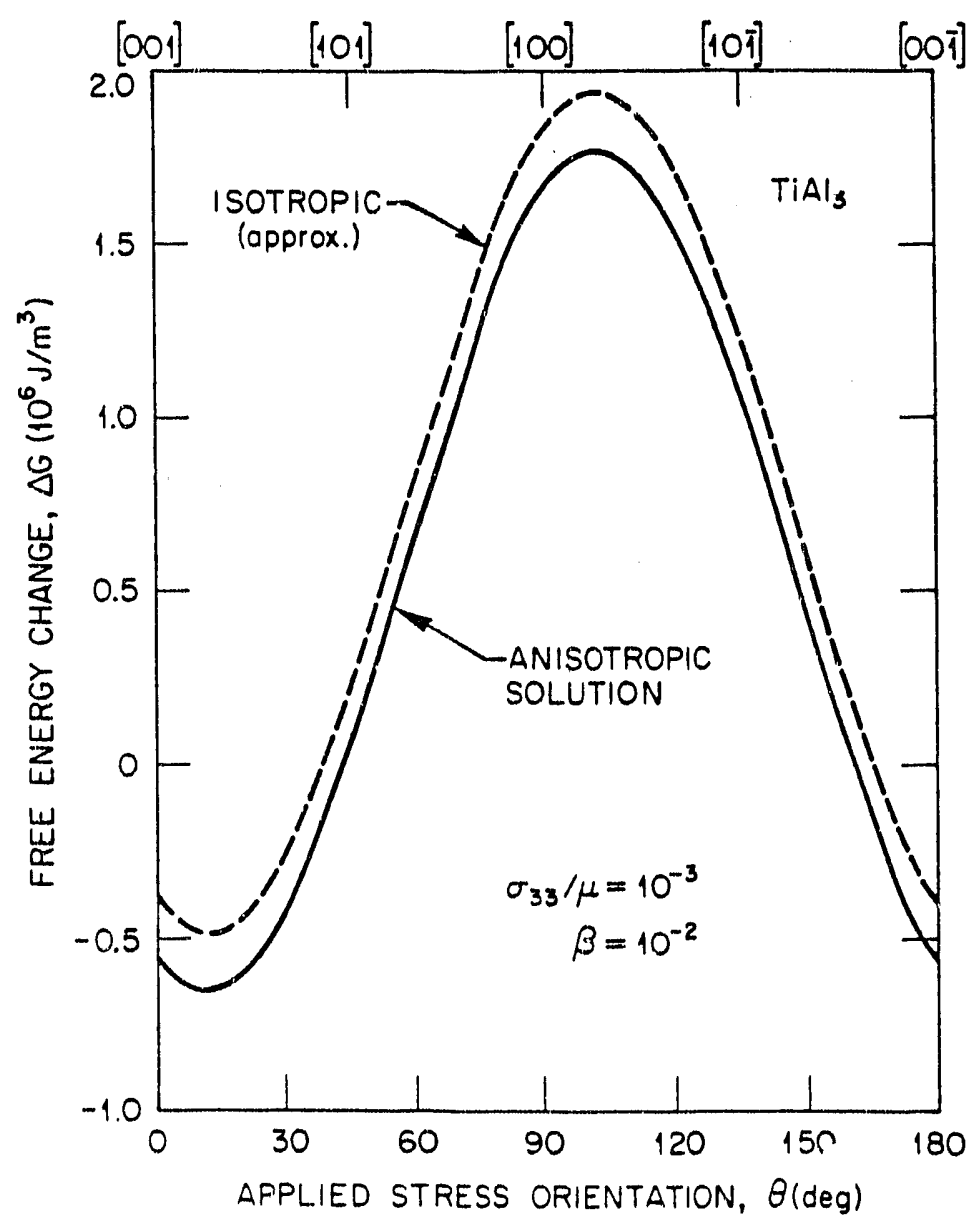

Fig. 4. Orientation dependence of the free energy change of twinning on the compressive stress axis. 
of rotation is [010]. The magnitude of compressive applied stress of $33 \mathrm{MPa}$ (the shear modulus, $\mu$, is $32.7 \mathrm{GPa}$ ), the aspect ratio $(\beta)$ of an elliptical twin (infinitely long along the $\bar{S}$ axis, perpendicular to the plane of shear) of $1 / 100$, and the shear strain of 0.05 (the twinning shears of TiAl and $\mathrm{TiAl}_{3}$ are 0.74 and 0.94 , respectively) were used for the calculation. The minimum value occurs near the [001] axis $\left(\theta=12^{\circ}\right)$. The measured compressive yield stresses of $\mathrm{TiAl}_{3}$ single crystals in the temperature range $25-900^{\circ} \mathrm{C} \mathrm{[3]} \mathrm{show} \mathrm{an} \mathrm{orientation} \mathrm{dependence,} \mathrm{which} \mathrm{is}$ consistent with the present calculation.

\section{Dislocation Mechanisms of Twin Formation}

On the basis of their transmission electron microscopy (TEM) observations in manganesedoped TiAl that each micro-twin was preceded by one single dislocation with 1/2[112] Burgers vector, Hug and Veyssiére [13] proposed a nucleation mechanism described as follows: a source produces a 1/2[112] superdislocation (RS in Fig. 3), which changes its slip plane at each turn (at its screw orientation). During the change of slip plane the dislocation transforms into a microwin.

We have recently identified the physical source for extensive dragging of superlattice intrinsic stacking fault (SISF) stemming from a [101] superdislocation in TiAl [14]. The threefold dissociation of a [101] superdislocation (RT in Fig. 3) results in two parallel strips of APB and SISF ribbons on the (111) plane. Using the calculated APB and SISF energies of 510 and $90 \mathrm{~mJ} / \mathrm{m}^{2}$, we determined the equilibrium widths alc $\mathrm{ng}$ the screw orientation to be 0.8 and $5 \mathrm{~nm}$, respectively. Owing to the interaction torque between the partial dislocations bounding the APB ribbon (Fig. 3 of ref. [14]), under an appropriate resolved shear stress, the 1/6[112] partial dislocation may glide extensively dragging SISF behind. With an appropriate multiplication mechanism this may lead to nucleation of a micro-twin.

\section{Twin Growth and Propagation}

The process of twin growth can be classified into two steps: the thickening process in the direction normal to the (111) plane $\left(\mathrm{K}_{1}\right.$ plane) and the lengthwise growth in the [115] direction ( $\eta_{1}$ direction). The former process requires a production of additional $1 / 6[11 \overline{2}]$ twin dislocations at the twin interface, which can be accomplished by various incorporation processes of superdislocations. The latter process of twin lengthening is controlled by the mobility of twin dislocations.

A schematic illustration of glide stress $\left(\tau_{x y}\right)$ and non-glide stresses $\left(\sigma_{x}\right.$ and $\left.\sigma_{y}\right)$ applied to a twin dislocation of edge type is shown in Fig. 5. The force on a dislocation is directly proportional to the glide stress component according to Peach-Koehler formula. The role of non-glide stress components in dislocation mobility is believed to be an indirect effect through a change of the dislocation core shape [20]. The coefficients for this anisotropic coupling effects, $S_{16}$ and $S_{26}$, are listed in Table II together with the elastic shear compliance, $S_{66}$, and the energy factor, $K_{e}$. Under the same applied stress, or the locally magnified stress field such as at a crack tip, the orientation dependent elastic shear strain, $\varepsilon_{x y}=S_{16} \sigma_{x}+S_{26} \sigma_{y}+S_{66} \tau_{x y}$, may be used as an indicator for the relative ease of slip and/or twinning.

\section{CLEAVAGE AND FRACTURE TOUGHNESS}

Figure 6 shows the positive pressure field and the shear stress field at a crack-tip of Mode-I type in TiAl. The magnitude of stress fields in Fig. 6 is in unit of $K_{I} / \sqrt{2 \pi r}$, where $K_{I}$ the stress intensity factor of Mode-I type crack, and $\mathrm{r}$ is the radial distance from the crack tip. We are concerned here with the (110) crack because of the earlier prediction [2] that the effectiveness of localized slip and twinning to stop the (110) crack is higher than to stop the $(001)$ crack. The anisotropic results were obtained on the basis of the solutions for an orthotropic symmetry [21]. The effect of elastic anisotropy is to extend the pressure field (for a dilatational transformation) along the crack itirection and the shear stress field (for slip or twinning) perpendicular to the crack plane.

The elastic shear strain, as discussed above, is shown in Fig. 7, which gives specific values in the parentheses for $(001)[110]$ slip, $S,(111)[112 \mid$ primary twin, $T$, and $(111)[\overline{11}]$ 


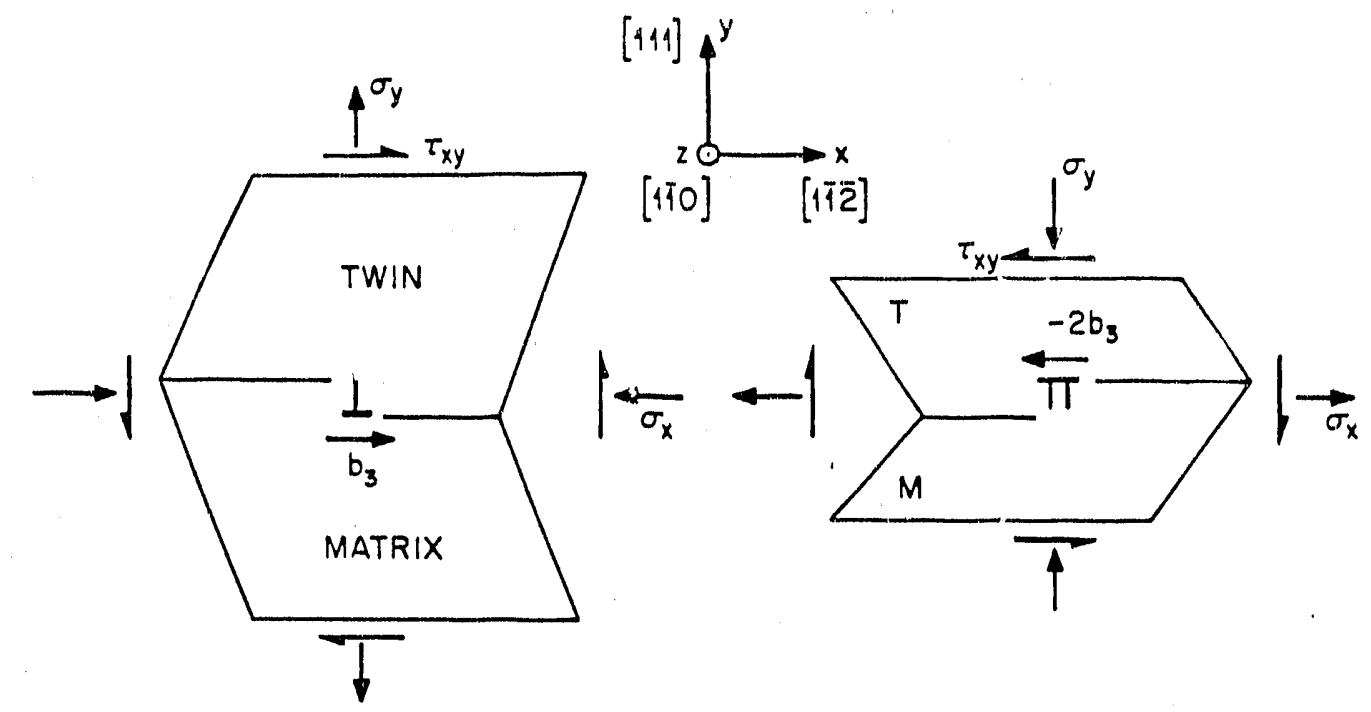

TWINNING

(primory)

ANTI-TWINNING

(complementary)

Fig. 5. Glide stress $\left(\tau_{x y}\right)$ and non-glide stresses $\left(\sigma_{x}, \sigma_{y}\right)$ on an edge twin dislocation.

Table II. Coherent (111) twin boundary energy and elasac properties of edge twin dislocations

\begin{tabular}{llccccc}
\hline & $\begin{array}{c}\text { Twin } \\
\text { type }\end{array}$ & $\begin{array}{c}\gamma_{\mathrm{t}} \\
\left(\mathrm{mJ} / \mathrm{m}^{2}\right)\end{array}$ & $\begin{array}{c}\mathrm{K}_{\mathrm{e}} \\
\left(10^{5} \mathrm{MPa}\right)\end{array}$ & \multicolumn{3}{c}{$\left(10^{-11} \mathrm{~m}^{2} / \mathrm{N}\right)$} \\
\cline { 4 - 6 }
\end{tabular}

complementary twin, $T^{\prime}$. For the purpose of comparison, the shear strain according to $\varepsilon_{\mathrm{r}} \theta=\mathrm{S}_{66}$ $\tau_{\mathrm{r} \theta}$ is shown with open circles. The value for (001) [110] slip, 0.31 , is unaffected by the normal stress components because $S_{16}=S_{26}=0$ in this case. The magnitude of shear strain for the primary twins is twice as large as that for the complementary twins. The effect of the normal stress, $\sigma_{\theta}$, alone on the shear strain is larger than the combined effect of $\sigma_{\mathrm{r}}$ and $\sigma_{\theta}$ by a factor of 2 , approximately, as far as twinning at the crack-tip is concerned.

It is commonly observed experimentally that the aspect ratio of deformation twins in TiAl and $\mathrm{TiAl}_{3}$ are very small, $\beta \leqslant 1 / 100$, i.e. very thin along [111] and long in the [112] direction. Accordingly, the role of normal stress, $\sigma_{\theta}$, in twin formation at a crack-tip is more important than that of radial stress, $\sigma_{\mathrm{r}}$. It may be concluded, therefore, from Fig. $7(\mathrm{~b})$ that the ordinary slip of $(001)$ [110] and the complementary twinning of $(111)[\overline{112}$, which are conjugate to each other, as well as the primary twinning of (111)[112] contribute significantly to the localized plastic deformation near a Mode-I crack-tip. This may constitute as the source for transformation toughening of shear type. 


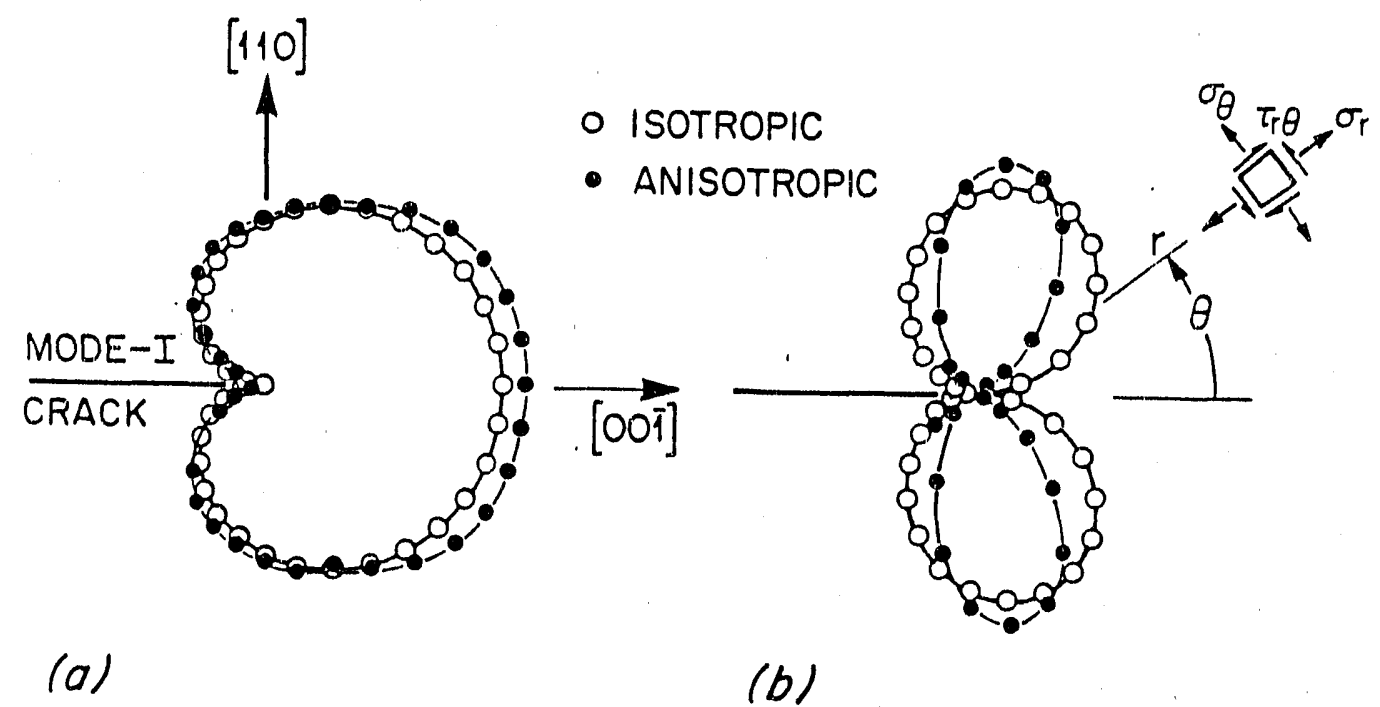

Fig. 6. Stress field at a Mode-I crack tip of (110) type in TiAl. (a) positive pressure, $\rho$, (b) shear stress, $\tau_{\mathrm{r} \theta}$.
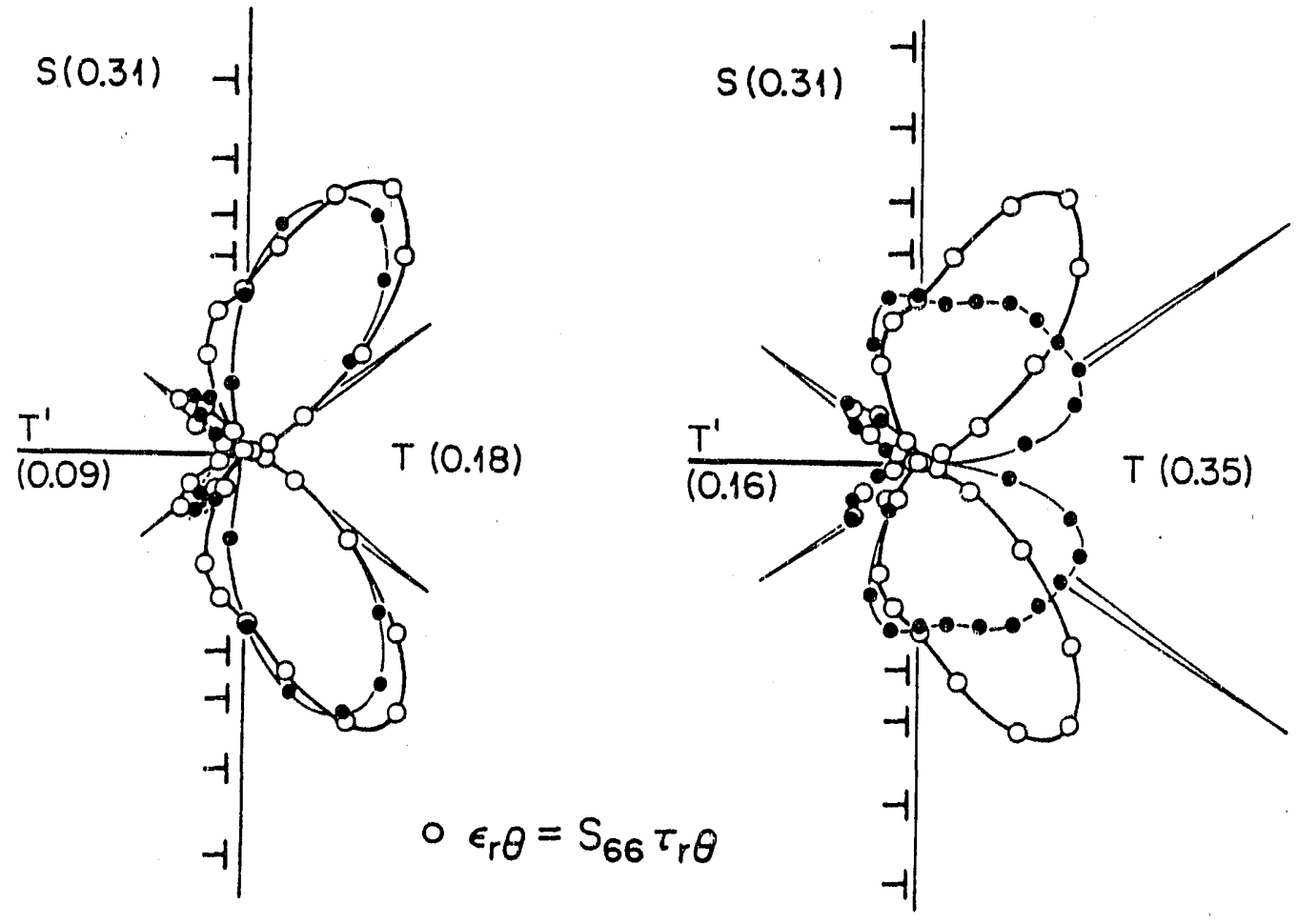

(a)

(b)

Fig. 7. Elastic shear strain field at a Mode-I crack-tip of (11C) type in TiAl. (a) effect of $\sigma_{\mathrm{r}}$ and $\sigma \theta$, (b) effect of $\sigma \theta$ only. 


\section{DISCUSSION}

It has been experimentally observed, in general, that deformation twinning can effectively strengthen a material under some circumstances and weaken it under others. This apparent dichotomy was the central issue of the last symposium on deformation twinning [22]. The twin morphology experimentally observed in deformation microstructures can exhibit a wide range of both thickness and aspect ratio $(\beta)$ leading to designation of macro-twins, micro-twins, and overlapping stacking faults. The demarkation thickness between a micro-twin and a macro-twin is quite arbitrary (e.g. on the order of ten lattice spacings), but the minimum thickness for a micro-twin should exceed not only qd, but also md, where $q$ is the number of crystallographic $K_{1}$ habit planes intersected by $\eta_{2}$ [5], $\mathrm{m}$ is the atomic stacking periodicity of $\mathrm{K}_{1}$ planes, and $\mathrm{d}$ is the interspacing of $\mathrm{K}_{1}$ planes. For example, in the case of (111)[112] primary twin system, the value of $\mathrm{q}=2$ is common to the both tetragonal structures, whereas the $m$ value is different, viz. $\mathrm{m}=3$ and $\mathrm{m}=6$ for $\mathrm{L}_{0}$ and $\mathrm{DO}_{22}$ types, respectively.

It is generally observed that a certain dispersion of fine micro-twins is conducive to toughening of a material, and a presence of massive macro-twins often leads to brittle fracture. In $\mathrm{TiAl}_{3}$ single crystals, which deform principally by ordered twinning, Yamaguchi et al. [3] concluded that the room temperature brittleness is due mainly to the lack of fine twins, and the increase in (001)[110] and (001)[100] slip activities with increasing temperature gives rise to an increase in fracture strain at elevated temperatures.

Likewise, the BDT reported in TiAl [5] is attributed to a combined effect of the (001)[110] ordinary slip and the ordered twinning of both types $\pm[112](111)$, primary and complementary twins. The mobility of $1 / 2[110]$ dislocations is expected to be low due to the directional Ti-Al bond, hence sessile. Energetically, a 1/2[T10] dislocation (TS in Fig. 3) can dissociate into $b_{1}$ and $-b_{2}$ partial dislocations by forming a complex stacking fault (CSF) ribbon on the (111) plane, i.e., $1 / 2[110]-1 / 6[\overline{2} 11]+1 / 6[\overline{1} 2 \overline{1}]$. According to the linear anisotropic elasticity, along the [110] screw orientation, we find a large interaction torque acting on the partial dislocation pair as shown in Fig. 8(b). The large interaction torque implies i non-planar dislocation core structure, which can give rise to the glide resistance of $1 / 2$ [110] dislocation on the (111) plane. Also shown in Fig. 8(a), is the schematic representation of 1/2[110] screw dislocation in its dissociated form according to the atomistic simulation study by Yamaguchi et al. [23], which gives the edge and screw components of each partial in the dashed and solid curves, respectively. The dashed curves indicate large inelastic displacemerits between the edge components of $\pm b 3 / 2$, or $\pm 1 / 12[112]$, which are mutually attractive on the (111) plane. The solid curves indicate, on the other hand, even larger inelastic displacement field between the mutually repulsive screw component, $1 / 4[110]$, of the like sign. The net repulsive radial force, $\mathrm{f}_{\mathrm{r}}$, is smaller than the tangential component, $f \theta$, because of the attraction between the edge components. Collectively, the symmetric agreement is extremely good between Fig. 8(a) and 8(b).

Only the calculated result of a (110) type Mode-I crack in TiAl is presented in this paper, where the role of (111)[10I] slip systems has been neglected. In the case of a (001) crack, while the effect of elastic anisotropy is found to be slightly more important as compared to Figs. 6 and 7 , no contribution from (001)[110] slip to crack-tip plasticity occurs as was mentioned in the earlier work [2]. The cleavage energy is predicted to be the lowest on the (100) plane, $4.6 \mathrm{~J} / \mathrm{m}^{2}$, in TiAl. In this case, however, twin planes are inclined to both crack the plane and direction. The additional results on $\mathrm{TiAl}$ and $\mathrm{TiAl}_{3}$ will be reported elsewhere.

As was discussed in the previous overview paper [2], the experimental data obtained by Kawabata et al. [24], who dealt with bending of TiAl single crystals, is consistent with the present prediction that the fracture toughness of (110) crack is higher than that of $(001)$ crack. More recently, Soboyejo et al. [25] has performed the crack-tip microscopy study of the binary $\mathrm{Ti}-34 \% \mathrm{Al}$ gamma alloy. They found that twinning was the dominant deformation mode in this polycrystalline alloy under monotonic and cyclic loads [25]. In order to assess the role of twinning in the intrinsic $\mathrm{BD}^{\mathrm{T}} \mathrm{T}$ of $\mathrm{TiAl}$ and $\mathrm{TiAl}_{3}$, information on the temperature dependences of elastic constants are needed.

The aralysis of crack-tip slip and twinning on the basis of the anisotropic elastic shear strain is applicable also to the cubic ordered structures (e.g. L1 2 type and B2 type). The mono-layer twins and the extended stacking faults at a crack-tip may be sufficient enough for the energy absorption leading to transformation toughening, as was indicated in $\alpha$-Fe by Kohlhoff and Schmauder [26] and in $\mathrm{CO}_{3} \mathrm{Ti}$ by Liu et al. [27]. Such an analysis for $\mathrm{NiAl}$ and $\mathrm{FeAl}$ is under way, which will be presented elsewhere [28]. 


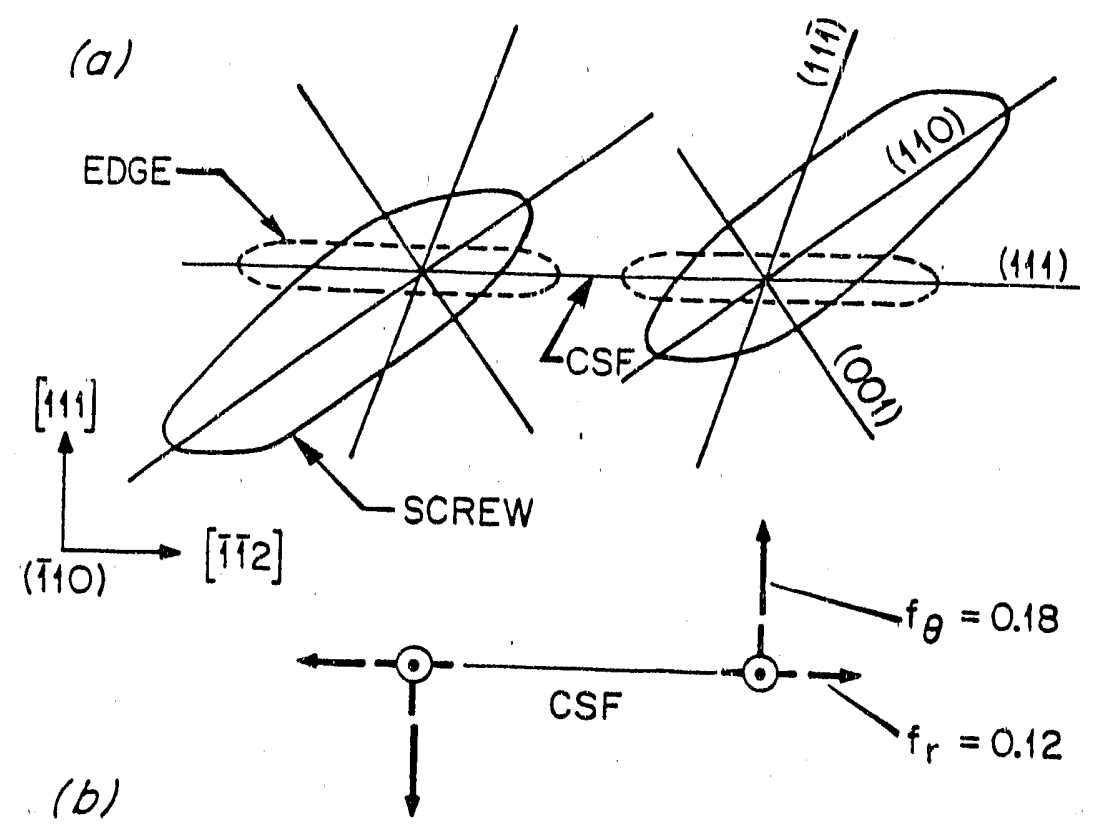

Fig. 8. Schematic representation of a $1 / 2[\mathrm{~T} 10]$ screw dislocation in the $\mathrm{L} 1_{0}$ structure. (a) the atomistic simulation for a L10 model alloy, Yamaguchi et al. [23], (b) the interaction forces calculated using the elastic constants listed in Table 1.

\section{ACKNOWLEDGMENTS}

The authors would like to thank C. T. Liu and E. P. George for helpful discussions, W. O. Soboyejo for releasing the information before publication, and C. L. Dowker for preparing the manuscript.

\section{REFERENCES}

1. J. W. Christian and D. E. Laughlan, Acta Metall. 36, 1617 (1988).

2. M. H. Yoo, C. L. Fu, and J. K. Lee, High-Temperature Ordered Intermetallic Alloys II, ed. C. T. Liu, A. J. Taub, N. S. Stoloff, and C. C. Koc!1, MRS Symp. Proc. Vol. 133, MRS Publication, Pittsburgh, PA, 1989, p. 189.

3. M. Yamaguchi, S. R. Nishitani, and Y. Shirai, High-Temperature Aluminides and Intermetallics, Proc. of Symp. 1989 TMS Fall Meeting, Indianapolis, IN.

4. M. H. Yoo, C. L. Fu, and J. K. Lee, Revue de Physique Appliquee (in press).

5. H. A. Lipsitt, D. Shechtman, and R. E. Schafrik, Metall. Trans. 6A, 1991 (1975).

6. M. Yamaguchi, Y. Shirai, and Y. Umakoshi, Dispersion Strengthened Aluminum Alloys, ed. Y. W. Kim and W. M. Griffith, TMS Symp. Proc., Materials Park, OH, 1988, p. 721.

7. B. F. Greenberg, V. I. Anisimov, and Y. N. Gornostirev, Scr. Metall. 22, 859 (1988).

8. S. A. Court, V. K. Vasudevan, and H. L. Fraser, Philos. Mag. A61, 141 (1990).

9. C. L. Fu and M. H. Yoo, Alloy Phase Stability and Design, ed. G. M. Stocks, D. P. Pope, and A. F. Giamei, MRS Symp. Proc. Vol. 186, MP.S Publication, Pittsburgh, PA 1990 (in press).

10. M. Yamaguchi, High-Temperature Ordered Intermetallic Compounds, ed. N. S. Stoloff, C. C. Koch, C. T. Liu, and O. Izumi, MRS Symp. Proc. Vol. 81, MRS Publication, Pittsburgh, PA 1986, p. 275. 
11. M. H. Yoo, J. Mater. Res. 4, 50 (1988).

12. T. Hanamura, R. Uemori, and M. Tanino, J. Mater. Res. 3, 656 (1988).

13. G. Hug and P. Veyssiére, Electron Microscopy and Fracture Research of Mate. .als, Intl. Symp., Dresden, 1989 (in press).

14. C. L. Fu and M. H. Yoo, Philos. Mag. Lett. 62, 159 (1990).

15. C. L. Fu, J. Mater. Res. 5, 971 (1990).

16. C. L. Fu and M. H. Yoo, High-Temperature Ordered Intermetallic Compounds II, ed. C. T. Liu, A. J. Taub, N. S. Stoloff, and C. C. Koch, MRS Symp. Proc. Vol. 33, MRS Publication, Pittsburgh, PA, 1989, p. 81.

17. J. D. Eshelby, Prog. Sol. Mech. 2, 89 (1961).

18. W. C. Johnson and J. W. Cahn, Acta Metall. 32, 1925 (1984).

19. J. K. Lee and M. H. Yoo, Metall. Trans. 21A, 2521 (1990).

20. M. H. Yoo, T. Takasugi, S. Hanada, and O. Izumi, Mater. Trans. Jpn. Inst. Metall. 31, 435 (1990).

21. G. C. Sih, P. C. Paris, and G. R. Irwin, Int. J. Fracture Mech. 1, 189 (1965).

22. The Role of Twinning in Fracture of Metals and Alloys a collection of five papers presented at TMS Symposium, Metall. Trans. 12A (1981), pp. 365-418.

23. M. Yamaguchi, Y. Umakoshi, and T. Yamane, Dislocations in Solids, Yamada Science Foundation, University of Tokyo Press, Tokyo, Japan, 1985, p. 77.

24. T. Kawabata, Y. Takezono, T. Kanai, and O. Izumi, Acta Metall. 36, 9163 (1988).

25. W. O. Soboyejo, P. B. Aswath, and J. E. Deffeyes, J. Mater. Sci. and Eng. (in press).

26. S. Kohlhoff and S. Schmauder, Atomistic Modelling in Materials - Beyond Pair Potentials, ed. V. Vitek and D. J. Srolovitz, Plenum Press, NY, 1989, p. 411.

27. Y. Liu, T. Takasugi, O. Izumi, and T. Takahashi, Acta Metall. 36, 2959 (1988).

28. M. H. Yoo and C. L. Fu, to be published.

\section{DISCLAIMER}

This report was prepared as an account of $w^{\prime}$ )rk sponsored by an agency of the Uniteo States Ger any agency thereof, nor any of their Government. Neither the United States Government nor anyes any legal liability or responsiemployees, makes any warranty, express or implied, or assum information, apparatus, product, or bility for the accuracy, completeness, or usefulness of any information, apparated owned rights. Referprocess disclosed, or represents that its use would not infringe price by trade name, tradernark, ence herein to any specific commercial product, process, or sor imply its endorsement, recommanufacturer, or otherwise does not necessarily constilute or imply its endoreof. The views mendation, or favoring by the United States Government or any ate or reflect those of the and opinions of authors expressed herein do rot

United States Government or any agency thereof. 

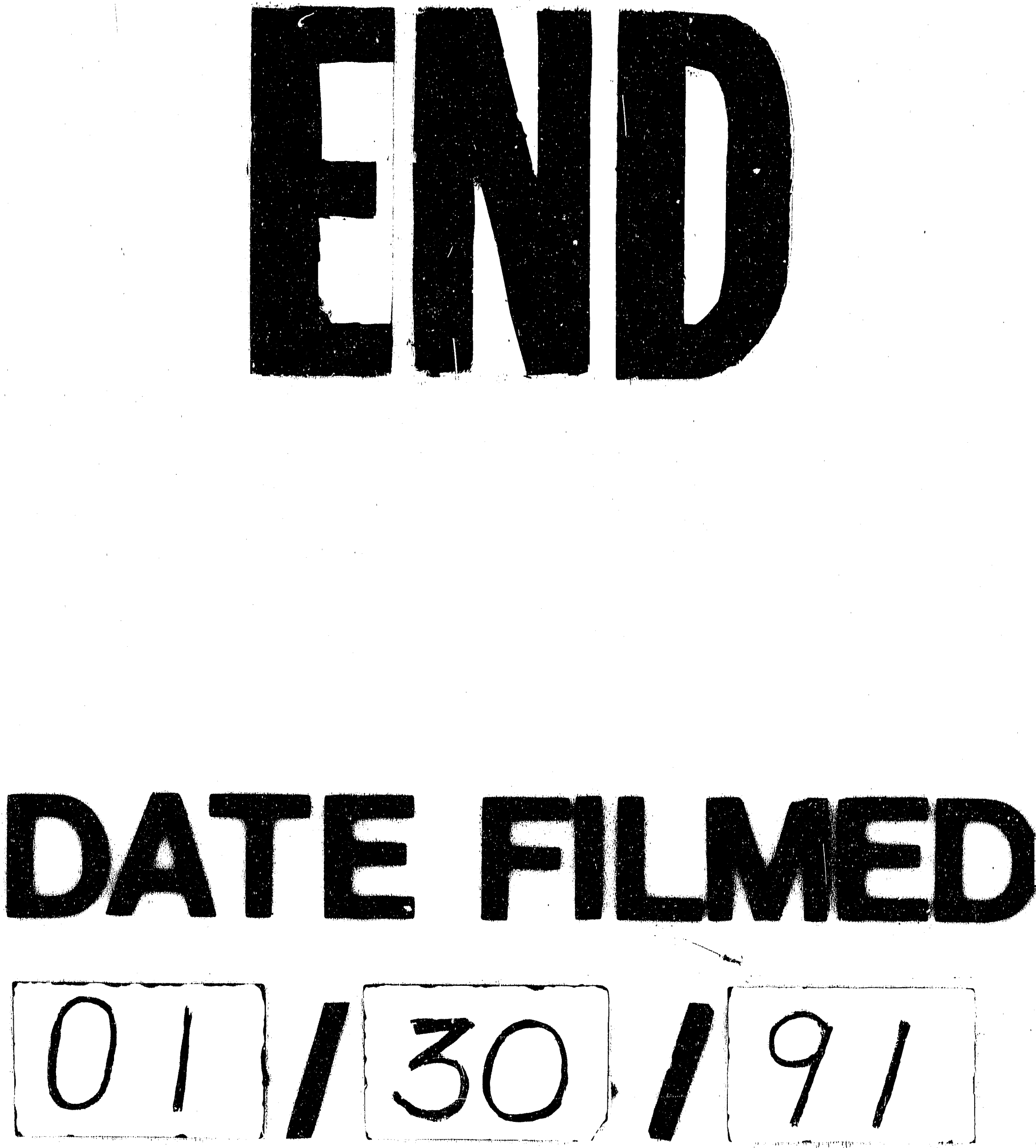
